\title{
Left Bank Cinema: Memories of History and the Experience of Time
}

\author{
Bijoy Philip VG*
}

\section{Abstract}

In this paper, I use two films - Les Statues Meurrent Aussi (Statues also Die, 1953) directed by Alain Resnais and Chris Marker and Marker's Sans Soleil (Sunless, 1983) as representatives of Left Bank cinema to show how they construct experiences of time and memory using various modernist strategies. Key to this is the use of a mental journey genre in modernist cinema and the construction of a facial dispositif which leads to a perceptual experiencing of inner states. Les Statues Meurrent Aussi is a key film in the history of French cinema as it highlights Resnais' and Marker's early commitment towards a politically avant-garde filmmaking style. The film was banned for many decades because it was highly critical of France's colonial interests. The film is also proof to the less emphasised collaboration between two pioneering directors and especially in their use of the essay film genre. Sans Soleil, on the other hand, is considered a philosophical masterpiece because of its meditations on time and memory. In taking these two films, I hope not only to demonstrate cinema's capability to generate affectivespatiotemporal states but also to highlight a piece of film history which is often misappropriated under the tag of the French New Wave.

Keywords: Memory, Time, Modernism, Cinema, Katabasis

\section{Introduction: Why the "Left Bank"}

When Richard Roud, (film critic, co-founder and director of the 1962 New York Film Festival) classified Alain Resnais (1922-2014),

*Jawaharlal Nehru University, Delhi, India; bijoy23_saa@jnu.ac.in 
Agnès Varda (b. 1928) and Chris Marker (1921-2012) as the Left Bank group of directors, he noted at the beginning of his article (1962) that classifications are only valuable if they tell us more about what is being classified. Roud wrote the article prior to the screening of their films at the National Film Theatre at BFI in London and also at a time when the names of at least Chris Marker and Agnes Varda were hardly known. Resnais, Marker and Varda together, and independently too, have a sizeable body of work, and enough correspondences and similarities between them to be considered an important group of film-makers with a significant intervention in cinematic history that is different from the French New Wave-the holy grail of European art cinema. The French New Wave directors carved out an actively visible and a muchcirculated commentary on the films they made with the explicit aim of reviving the post-war French film industry and bringing about a radical shift in film aesthetics from the expensive Hollywood studio system. The Left Bank directors never aspired for such an organized definition, and in fact their work is best described through a series of shared aesthetic and political affinities which when put together in retrospect have made significant contributions through six decades towards answering certain fundamental questions about cinematic modernism and issues regarding a cinematic experiencing of memory, time and history.

The correspondence that Left Bank directors sought to achieve between image and memory is central to understanding the aesthetic and ideological implications of cinema within the context of modernism. For the post World War II period, Nadine Boljkovac (2013), using a Deleuzian framework, discusses the 'affinity between the work of art and the art of resistance', and contextualises modernist cinema's need to acknowledge this violence to thought and its resistance to represent time conventionally. She highlights cinema as an artistic medium which has the capacity to represent a differential, untimely time of 'virtual becomings', which unfolds between the "immediate past and the future that is still to arrive" (p.15). This non-hierarchical time gathers the artistic potential to convey a split in time or rather the linear perception of memory and history. In this paper, I would be considering Chris Marker's Sans Soleil (1983) and Les Statues Meurrent Aussi/Statues also Die (1953) which was co-directed by 
both Marker and Resnais. Though the term Left Bank cinema evokes Marker, Resnais and Varda, in this paper I would be limiting my focus to the first two directors to demonstrate how they construct an experience of time and memory in their films through modernist stylistic techniques which lead to the fragmentation of the real.

Fragmentation of reality can be argued as the key stylistic feature of all modernist art which would then give rise to its various ideological consequences, and especially in cinema, this would be a critique against a linear representation of time through narrative. András Bálint Kovács (2008) notes that "the idea of reality that modern art reflects is always filtered through an abstract concept which it tends to consider more real than empirical reality" (p. 121). Thus, the composition of modernist artworks through the principle of abstraction is also self-reflexive of its own construction of a fragmented reality. The medium no longer remains transparent and does not sustain an immediate and objective representation of reality but becomes reflective and subjective. In modernist cinema, the process of fragmentation is not only limited to the narrative but also seeps into the audio and visual layers of the film. Deleuze's writings on the movement-image (1986) and time-image (1989) identify various aspects of audio-visual fragmentation as a key characteristic of modernist films. Instead of a psychological framework that governs the representation of reality in the narrative of classical cinema, modernist cinema exhibits a radical disconnectedness between its surface elements. There is no longer an empirical or spiritual reality that motivates a linear progression of action but only an arbitrary relationship between its independent surface elements, and thus continuity becomes the point of contention in modernist cinema. As Kovacs (pp. 120-128) notes, continuity cannot be perceived either in the film's narrative or in its audiovisual texture. Thus, my discussion of modernism in Left Bank cinema also revolves around the fragmentation of both narrative and the audio-visual textures of these films.

When it comes to modernist aesthetics of self-reflexivity and fragmentation, there is no other place which is more fertile for this discussion than the essay film which is characterised by its digression from genre conventions and most importantly in its 
subjectivity which is routed through the personal while being historical and collective at the same time. When the term essay film is used, it is most often categorised with the documentary genre and in film festival circuits. All these fall into the non-fiction category. While in documentary films, the viewer and the narrator explicitly take their position outside the film in an objective manner, the spectator is interpellated into the narrative of the essay film.

To understand this better, one can go back to Resnais' Hiroshima Mon Amour's (1959) "film within a film" during the opening sequence, where archival images are used as the "woman" recounts what she claims to have seen in Hiroshima during the aftermath of the bombardment. By including images that speak of their archival quality within a fictional setup, it becomes impossible from a spectatorial position to be absorbed and carried away by the images. Instead, the viewer is shocked by the sudden intrusion of the "real" into the fictional setup. While the images make evident their prosthetic nature, they are channelised through the subjective albeit fictional viewpoint of the woman with whom we identify personally. It is precisely this personal expressivity that characterises the essay film much like the written essay where no matter how objective the topic of the essay is, there is always the indelible " $\mathrm{I}$ " that leads to a blurring of boundaries between the personal and historical or the subjective and objective. While in Resnais' Night and Fog (1956) it was the experiential account of Jean Cayrol who himself was a Holocaust survivor, in his Guernica(1950) it is Paul Eluard's poem that helps Resnais achieve this quality. Like the audio-visually dissociated images of modernist cinema, the essay film's sound and visuals have a greater tendency to remain dissociated than in documentary films which are driven by factual narration.

\section{Orphic Descent and the Facial Dispositif}

Left Bank cinema's interpretation of modern memory closely follows a modernist trajectory and situates it as existing outside the individual and hence as an archive. Russell. J. A. Kilbourn (2010) in his work foregrounds a modern archival consciousness that is shaped through external mnemotechnical supplements. In his 
analysis, he highlights that modern memory whether "individual or collective is by definition 'exterior', hypomnesic and archival" (p.20). Interestingly, he cites J.J. Long's study on Walter Benjamin's student, the German writer W.G. Sebald, and draws our attention towards Long's formulation of the archival subject of modernity as someone who "compensates for his lack of memory by substituting the archive for interiority" (p.20). He is in the most literal sense an archival subject" (p. 20). Kilbourn says that the archive is "spatial, static and external to the human psyche" (p. 21). The modern archival subject externalises inner psychic planes, by giving a spatial dimension to a mental plane. The work of the Left Bank film-makers demonstrates precisely this feature in the construction and realisation of modern subjectivity.

Kilbourn describes the mental journey genre as the articulation of inner psychic states through his formulation of the concept of psycho-katabasis which is a journey of the self-quest inward. It falls outside the purview of chronological time and it seeks to escape time's flow and as Kilbourn points out, "Orpheus's mythical journey is unavoidably rendered in the distended duration of cinematic montage" (p. 52). He highlights katabasis as a narrative form which "replicates the classic structure of the mythical underworld journey in which the un-dead hero travels to the land of the dead in order to acquire some special knowledge that will help him in his endeavours in life" (p. 34). He identifies the literarymythic katabasis as one of the oldest narrative models in different cultures and as a

journey that takes place within an underworld that is an exteriorized 'projection' of a protagonist's putative interior world" which is also "the domain especially of the unconscious, memory and dream" . .. a journey which turns inward: a quest for selfknowledge that takes the place of the Bergsonian, present-tense "sensory-motor situations" of Deleuze's action image. (p. 31)

Moreover, I argue that within this cartography of mental planes the face emerges as a cinematic dispositif which creates a perceptual experiencing of inner states. Thus, I also demonstrate how the "facial dispositif", a term proposed by Noa Steimatsky (2017), 
becomes another important aspect of Left Bank cinema. By facial dispositif, she means, "the face as a paradigmatic perceptual "disposition" - a flexible configuration of attitudes, relations, and discourses, comprising the very consciousness of the medium, that guide and frame the critical attitude" (p. 3).The face and its closeup is a vital ingredient of both these concepts. As Steimatsky observes using both Balázs and Epstein, the close-up of the face "elicit(s) a subjective consciousness from its objects, animate and inanimate through microphysiognomic functions", and produces an "immediate and unmediated inner experience of duration which is, in this Bergsonian vision, the dimension of consciousness" thus leading to a "departure from chronological temporality" which is "liberated from linear and spatial calculation, from succession and progression" and "the artificial segregation of past and present" (pp. 28-29).

\section{Les Statues Meurrentaussi- Descent into Forgotten Histories}

Resnais's and Marker's Les Statues Meurrent Aussi/Statues also Die (1953) is an important film where we can see the workings of the facial dispotif and katabasis. In this film, the faces of the statues and artifacts become an affective site of pure communicability and exteriorised subjectivity. The facial dispositive which Resnais and Marker develop in the film creates a subjective experiencing of the inanimate figures within a scopic field between the individual and the collective. The face becomes a site of affective meaning and memory for which Les Statues Meurrent Aussi can be cited as an early example. In Les Statues Meurrent Aussi much of this is achieved through Marker's commentary and Resnais' characteristic montage by which static objects are rendered with a life-force that matches the living gaze. At the beginning of the film, Marker announces:

An object dies when the living glance trained upon it disappears. And when we disappear, our objects will be confined to the place where we send black things: to the museum. 
Marker's commentary seeks to revitalise the sculptures and art objects with a renewed gaze and restore their affective histories. Soon after the above introduction to the film, we see multiple shots of African art objects being classified in the museums, locked away as skeletal remains of "unknown origins". The camera cuts into a subjective shot where it is placed within a glass enclosure, upon which various visitors look at and pass by with curiosity. The gazes are met with curious or nonchalant stares of white faces. The spectator is directly met with the gaze and at once objectified, until the face of a black woman appears and in a reverse shot, the frame cuts to that of an African mask. This would be one of the many face/mask assemblages which would be constantly deployed throughout the film.

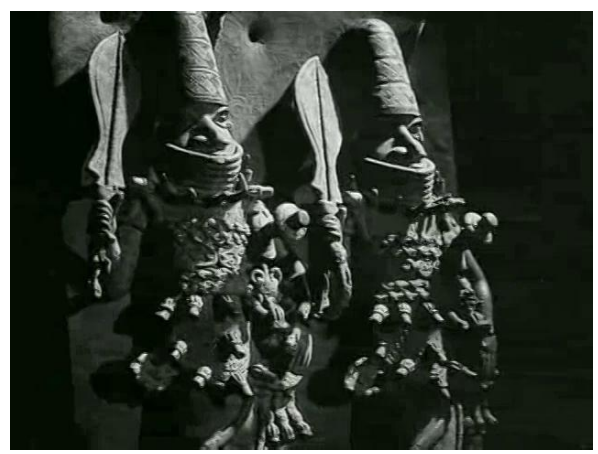

Fig 1 Still from Statues also Die

Deleuze and Guattari highlight that the face is part of an "imperial abstract machine", "overcoding the subject". The mask being part of the "pre signifying sign regime", "pushes the head back into the body and traces a relationship along the path of becoming animal". On the other hand, the Face or the white man's face decodes the head from the body and separates it into a "new holey surface system" in contrast to the "volume cavity system" of the pre signifying tribal regime in which the body is emphasised with a highly "haptic, tactile and proprioceptive assemblage". In this manner, Deleuze and Guattari consider the production of the face as a deterritorialising process of colonialism which moves the human from the pre signifying tribal regime into the anthropomorphic stratum of signifying and subjectifying sign regime. In this process of deterritorialisation, there is a move away 
from the body, away from corporeality and over-coded by the European signifying sign regime in which the white man's face becomes the primary signifier and the primary means to overcode the earlier tribal regime (1987/2005, pp. 167-190). Marker's and Resnais's visual and narrative strategy is to trace back the predominance of a pre-signifying tribal regime that was deterritorialised.

For Deleuze and Guattari, dismantling the face means to "no longer look into the eyes, but to swim through them, to close your eyes, to close your own eyes, and make your body a beam of light moving at ever-increasing speed" (1987/2005, p. 187). Marker and Resnais seek to dismantle the signifying sign regime of the face by developing an affective gaze while considering the African artifacts. As mentioned in the earlier sequence, the voiceover follows the reverse shot and the cut back from the African mask to that of the Black woman who stares at the tribal mask in the museum and the voice over notes:

It is its smile of Reims that she gazes upon. It is the sign of a lost unity where art was the guarantee of an agreement between man and world.

The smile of Reims conjures an affective encounter with that of the Black woman. Between the gaze of the black woman and the smile of Reims, a line of flight is traced through which Marker and Resnais enter into "Africa, that ancient land of ancestors" in a katabatic descent into interred history.
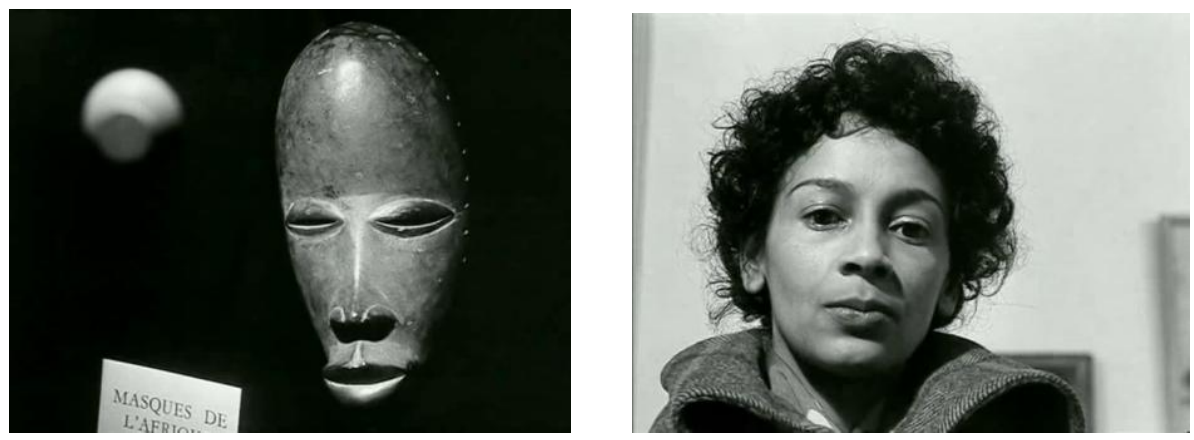

Fig. 2 Stills from Statues also Die 
A series of montage sequences foreground Africa through artworks that present the continental formation through centuries. Marker and Resnais offer a postcolonial critique of the West's oriental fetishisation of the continent, "Black was already the color of $\sin ^{\prime}$. In the sequence which follows, this diabolical land opens up treasures of an ancient civilization. The montage unfolds without commentary only accompanied with Guy Bernard's dramatic symphony of polyphonic tones that bring to life static shots of leopards, soldiers, masks and ritualistic sacrifices. It reminds us of Resnais's metrical montage sequence of Guernica (1950) in which he combined a dramatic background score with selective zooming and panning that infused Picasso's still drawings with an affective quality of terror, and a movement of pure duration that conjured stasis into movement - a technique which Marker later develops through the photograms of LaJetée (1962).

The essayistic flow of the film develops an argument that forces one to see these objects not as mere enigmatic artifacts but as cultures which have been long forgotten. The arguments strive to make a point - that these objects are not symbolic of gods or demons, but a flow of time, a way of life, a cult of the world wherein a statue does not indicate the presence of a god but becomes a prayer in itself. It is presented as the true black art which should puzzle the West. The film says that in this world where everything is art, it does not make sense to classify them as objets des arts.

One of the primary photogenic mechanisms that are in operation in the film is inducing the objects and artefacts with a corporeal charge, which Epstein defined as "magnification" or "grossissement" in French which also denotes the condition of pregnancy in the French language. Steimatsky notes that this implicates that the magnification achieved through the close-up is not simply a "quantitative or geometric measure" but also "invokes a sense of becoming, of a new and ultimately independent life" one which is "future life embedded in the pregnant form" (p. 36). Marker's and Resnais' katabasis in Les Statues Meurrent Aussi is the descent into the annals of misappropriated history where Western cultural hegemony has robbed subjectivity of a significant chapter in human history. 


\section{Sans Soleil: Marker's Ode to Memory}

Chris Marker's Sunless has its title borrowed from Modest Petrovich Mussorgsky's (1839-1881) Sunless song cycle. Marker opens the film with a quote from T.S. Eliot's poem Ash Wednesday foregrounding the primary mediation of the film "Because I know that time is always time. And place is always and only place," thus evoking a strong modernist sensibility of spatio-temporal incongruity. The script of the film is in the form of a letter that a fictional Sandor Krasna writes to an unknown woman about his travels around Africa, Japan, San Francisco, Guinea-Bissau, Iceland, and the Cape Verde islands. The letter is read out in a voice-over format by Alexandra Stewart in the English version of the film around miscellaneous visuals shot by Marker himself, some by his photographer friends along with some archival footage. The epistolary format of the script proceeds in a Proustian manner where one image plucked from a random mnemonic node leads to another as if each one is prompted through Madeleine cues where a sensation prompts an avalanche of memories. Sunless is permeated by cultural symbols that seem to be long forgotten above the bustling cityscapes of Tokyo, forgotten episodes of history beneath the impatient faces of the fishermen at Cape Verde islands or in the eyes of women at Guinea-Bissau. The trajectories are so infinite that it becomes impossible to digest the film in one sitting. The dissociation from the visuals and the soundscape is so much that one can read the script alone or mute the sound and just see the visuals themselves as an experiment and still leave satisfied at the end of the exercise

This form of "mental journeying" into the "underworld" in the katabatic scheme can be considered as the essay film's predominant form. This is mainly achieved through the essay film's "pronounced subjectivity" or "enunciating position" (Corrigan, 2011, p. 30) that blends in with what Laura Rascaroli terms the essay film's "disjunctive ethos" (2017, p. 144) that facilitates fragmentation and non-linearity. The face becomes a site of subjective expression and occupies an inter-subjective space between the private and the public, the personal and the historical. The face becomes a mode of spectatorial interpellation in the essay 
film while in the fictional, it becomes a locus of desire, which the historical constantly denies.

To call Marker as an archivist of the $20^{\text {th }}$ century will not be, by any means, an exaggeration. Over the course of his career, Marker accumulated thousands of images and it will not be wrong to state that what we are able to see through his films and published collection of photographs would only be the tip of the iceberg. The reason behind taking this guess is primarily because of the online archive he had created-Immemory and his online museum on the virtual world of Second Life called Ouvroir and this is apart from the personal collection of Marker which is presently being archived by the Cinémathéque Française. The combined magnitude of these two gigantic repositories gives us enough evidence on Marker's persistent endeavour towards capturing and archiving faces, spaces and objects that don the $20^{\text {th }}$-century landscape. For the purpose of this discussion however, I will limit my focus to particular sections from Sans Soleil that highlight Marker's mental journeying as a means of subjective ethnography.

Marker has a habit of meditating on the kind of travel he undertakes and is captured by the figure of Plume from Henri Michaux's novel "A Certain Plume". An introduction to the book states that Plume "drifts from one thing to another, losing shape, taking new forms, at perpetual risk from reality" (Michaux, 2018). Marker (2016) explains elsewhere in his photo-essay Koreans his particular affinity to this form of travel driven through chance encounters.

There are different ways of traveling - the Barnabooth way, the Genghis Khan way, the Plume way (invented by Henri Michaux). For example: accepting the disorder of rhymes, waves, shocks, all the bumpers of memory, its meteors and undertows. Chance has intuitions, which shouldn't always be taken for coincidences. The country where you have just set foot delegates you a woman's face which sums it up already, and names it. (A great ship whose prow slowly turns round and stares at you, like a horse.) Its name is Sweetness (Marker, 2017). 
The fictive traveller of Sans Soleil is not the usual travel blogger, for his interest in capturing images is not because the images themselves stand for anything spectacular but rather he is interested in them for their "fragility". In Sans Soleil's opening sequence on the boat, our traveler emphasises the mundaneness of his memory project - collecting images that share the fragility and transience of memories as if transmitted right from the brain and projected onto the screen, without any specific order, as memory objects whose meaning gets reshaped depending on why and how they are recalled in the present. Alexandra Stewart, the narrative voice in Sans Soleil notes:

He liked the fragility of those moments suspended in time. Those memories whose only function had been to leave behind nothing but memories. He wrote: I've been round the world several times and now only banality still interests me. On this trip I've tracked it with the relentlessness of a bounty hunter.

He talks to us in absentia via a letter, which may suggest that we cannot be sure of the physical whereabouts of this traveller. Taking into account the leaps he makes between time and space, it could be assumed that he must have left our world already, leaving us with a set of images too grainy to decipher if it were not for his accompanying note, the "letter" which is the narrative of the film. In fact, this is exactly how Marker's career and life can be summarised, just that he has hardly left any accompanying note apart from his images.

Marker stratifies his images that weave in and out of each other in Sans Soleil. Immediately after the opening credits of the film what we see is the grainy image of three children walking through a grass-field for a couple of seconds. The narrator who is also the female voice reading the letter tells us that "the first image he told me was of three children in Iceland in 1965". The screen cuts to black while the voice-over tells us that "for him it was the image of happiness... and that he had tried several times to link it to other images". This is immediately followed by a brief shot of a fighter jet on an aircraft carrier without any explanation. This narration underlies the very purpose of Sans Soleil's montage, where the 
interstice between two images is filled by an affective and intuitive logic of memory - nonlinear and fragmented.

Another key feature of Sans Soleil is how Marker takes an apparently non-descriptive everyday image and using his words transforms the monotone image into something poetic, loaded with polyphonic meanings and sensations where the personal makes an essayistic leap to the collective and historical. For example, looking at the sleepy faces of his co-travelers on the boat, Marker wonders if "waiting, immobility and snatches of sleep, curiously all that makes me think of a past or future war", sending us back to the second image of the aircraft carrier he had surreptitiously implanted at the beginning of the film. However, the first image of the children in Iceland and its connection with happiness would only emerge towards the end of the film. Fragments of images function like madeleines in Sans Soleil, similar to Amad's formulation of the cinematic counter-archive which functions through similar principles of "disorder, fragmentation and contingency" as mentioned at the beginning of the chapter.

Marker's itinerary of travel in Sans Soleil might seem like a journey to explore contrasts between the developed nation of Japan and third world countries like the Bijagós Islands off the coast of the African nation of Guinea-Bissau, or Cape Verde on the NorthWestern coast of Africa or the deserts of Sahel close to Sahara. However, he tells us that his "constant comings and goings" are not a "search for contrasts" but they are "journeys to the two extreme poles of survival". He explores the faces of people, cultures and festivals, and colonial histories not as an ethnographer in the usual sense of the word but rather as the counter-archivist where his attempts, as he says, would be to understand the "function of remembering". However, for Marker this is not merely a pet memory project. Rather, he dives into history through sensations, images, daily observations, and in short, all those subjective aspects (read memories) which are forgotten while writing histories.

For example, in the Bijagós islands, he observes, zooming in on the faces of women, that "it's the young girls who choose their fiancées". At the same time, he dives into its colonial history of Portuguese occupation and the revolutionary leaders who led the guerilla fight against the occupying forces not through objective 
accounts of the struggle but by using archival footage and through his montage isolating certain elements such as facial expressions or hand gestures. He then uses his commentary to point out interstices that would have otherwise been missed if not for his essayistic intervention into that which has already been missed from the written pages of history.

While Marker occasionally gives us glimpses of landscapes in his travelogues, the majority of the visuals that he aggregates are faces from the everyday thus making them the film's primary dispositf through which he explores the sudden shifts, violent breaks and historical fissures of modernity. The faces from a bar in Namidabashi followed by those of the fishermen who stare right into the camera from The Jetty on Fogo, in the Cape Verde Islands abruptly cut with the cracked earth of Sahel and many more such vertigo inducing combination of spaces, portraits and objects break into museomatic units within which one navigates in "plume" fashion. From a working-class bar in Namidabashi which Marker identifies as a "place that allows people to stare at each other with equality", he cuts to the faces of fishermen and women waiting for the fishing boat at the Jetty on Fogo in Cape Verde islands, who share the same wrinkles of working-class hardship on their faces. He draws our gaze to theirs and notes "How long have they been there waiting for the boat, patient as pebbles but ready to jump?" At this point, he starts capturing the moments when these people men, women and children begin staring into the camera as he asks us "Frankly, have you ever heard of anything stupider than to say to people as they teach in film schools, not to look at the camera?" This look into the camera or the return of the gaze eliminates the inner distance the spectator feels from the screen and incorporates the spectator as a subject. Noa Steimatsky notes

Expression is something recognized-as a face is, simply, recognized - but when an object, or image, thus seems to return our gaze, there is also a way in which it is defamiliarized: it disconcerts us and makes us conscious of our own look (2017,p. 34).

Marker makes it a point to observe the everyday faces and the bustling cityscapes of Tokyo as a fertile ground to capture interesting portraits. In one sequence, Marker stops by a street side 
restaurant in Tokyo, where he sustains another close-up of its chef whom he calls Mr Yamada who practises "action-cooking". Observing his carefully practised movements over the pan, Marker remarks "one could meditate usefully on certain fundamental concepts common to painting, philosophy, and karate," and that "Mr. Yamada possessed in his humble way the essence of style". Next, he shifts his focus to faces on Japanese television which he calls the "memory box", where he shows us a montage of Japanese horror movie sequences especially focussing on the "faces of horror" that appear on the screen. Here he makes an allusion to Marlon Brando's line from Apocalypse Now (Coppola, 1979) "Horror has a face and a name... you must make a friend of horror". There are innumerable examples similar to this throughout the film from the streets of Tokyo, departmental stories and underground railway lines where, as he says "A face appears, disappears... a trace is found, is lost".

The significance of quoting Brando's line would appear much later as he explores the freedom struggle of Guinea Bissau started by Amilcar Cabral who was assassinated by his own party members. The struggle was then led by his half-brother Luis Cabral. Marker begins the sequence by showing a bit of black and white footage of Amilcar Cabral as he leaves the island for the last time. This scene is immediately followed by the colour footage of Luis Cabral arriving on the island fifteen years later making the same waving gesture; by this time Guinea Bissau had gained its independence from the Portuguese. Marker shows us the footage of Luis Cabral decorating his guerilla fighters with military honours and we see the men weeping. Just at this moment, Marker intervenes and corrects our perception and says that those tears were not tears of joy but rather they were of a wounded pride as they felt they hadn't been promoted high enough. Marker draws our attention to the close-up of the disgruntled guerilla fighters and says:

And beneath each of these faces a memory. And in place of what we were told had been forged into a collective memory, a thousand memories of men who parade their personal laceration in the great wound of history. 
As a consequence, we are told that Luis Cabral was imprisoned the following year and that the weeping generals would have taken power. The land Cabral liberated would fall into tyranny once again. Images from this violent split and another war fill the screen and Marker zooms in on a wounded limb being eaten by worms and quotes Brando's line on giving horror a name and a face once again. Marker notes:

That's how history advances, plugging its memory as one plugs one's ears...She doesn't care, she understands nothing, she has only one friend, the one Brando spoke of in Apocalypse: horror. That has a name and a face.

Marker concludes this analysis by remarking on the amnesia that the future is plagued with and which history distributes to its "recruits", through the tragedy of Guinea Bissau-what Amilcar suffered repeated itself on Luis Cabral.

Marker is also keenly aware of the prosthetic nature of his memories. To illustrate this aspect, he invents a fictional character Hayao Yamaneko who has an image synthesiser. Marker calls Hayao, his friend and is amused by his image synthesiser. He treats various archival images from history through the synthesiser which then breaks it into multicoloured hues and leaves only a rough outline of the original image. Marker uses the image synthesizer to distort the clashes of the 1960s or generally "television images" as he describes them. Marker says that because the "images of present don't change, then change the images of the past". By "changing" these images, he recalls the power of the cinematic image or digital technology to alter and mediate our experiences of the past which the visual artist is capable of doing. Technology becomes the means by which history is mediated by breaking down its textures into prismatic hues of red, blue and green which become the affectations of an externalised memory and subjectivity. During various instances, Marker feeds the images we have already seen in the film through this machine which in a way is a reflection of his own process in Sans Soleil-an audio-visual treatment of images from the past and a remediation of history through memory. Marker makes an allusion between Hayao's machine and Tarkovsky's "zone" from Stalker - the delirious memory place that 
suspends time and where images become highly deceptive, a quality which Marker attributes to images and memories themselves and which he tirelessly pursued throughout his career.

Memories must make do with their delirium, with their drift. A moment stopped would burn like a frame of film blocked before the furnace of the projector. Madness protects, as fever does.

\section{Conclusion}

Following Deleuze, if movement in all arts can be framed as the movement of thought through sensation (Flaxman, 2000, p. 18-19), it is indeed inexplicably linked to the movement of time and, memory can be experienced through and in-between these movements. By taking Statues also Die and Sans Soleil as examples of Left Bank cinema I have attempted to show how these directors saw in the art of moving images the sculpting of time, and not just individual time, but that which merges with the collective and the historical. For these directors, the boundaries between various arts are fluid as their vision being rooted in the aesthetic and temporal concerns of modernism.

\section{References}

Boljkovac, N. (2013). Untimely affects: Gilles Deleuze and an ethics of cinema. Edinburgh: Edinburgh University Press.

Corrigan, T. (2011). The Essay Film from Montaigne, after Marker. Oxford: Oxford University Press.

Deleuze, G. (1986). Cinema 1: The movement-image. London: Continuum.

Deleuze, G. (1989). Cinema 2: The time image. London: Continuum.

Deleuze, G., \& Guattari, F. (2005). A thousand plateaus: capitalism and schizophrenia (B. Massumi, Trans.). Minneapolis: University of Minnesota Press

Flaxman, G. (2000). The brain is the screen: Deleuze and the philosophy of cinema. Minneapolis: University of Minnesota Press.

Kilbourn, R. J. (2010). Cinema, memory, modernity the representation of memory from the art film to transnational cinema. London: Routledge.

Kovács, A. (2007). Screening modernism: European art cinema, 1950-1980. Chicago: University of Chicago Press. 
Marker. (2016). Coréenes. Retrieved from https:// www.markertext.com/ coreenes.htm

Michaux, H. (2018). A certain plume. Penguin Random House. Retrieved from https://www.penguinrandomhouse.com/books/563026/acertain-plume-by-henri-michaux-afterword-and-translation-from-thefrench-by-richard-sieburth/9781681372266/

Rascaroli, L. (2017). How the Essay Film thinks. New York, NY: Oxford University Press.

Roud, R. (1962). The Left Bank. Sight and Sound, 33(2), 24-27.

Steimatsky, N. (2017). The face on film. New York, NY: Oxford University Press.

\section{Endnotes}

${ }^{1}$ Photogénie does not simply describe - as one colloquially does - persons who turn out nicely in photos. Rather, it is a transformative quality superadded to things in cinematographic reproduction by the "intelligence of a machine" (Steimatsky, 2017, p. 34). 